\title{
Critical zirconia amount to enhance the strength of alumina
}

\author{
Wei-Hsing Tuan *, Jiang-Rung Chen, Chang-Ju Ho \\ Department of Materials Science and Engineering, National Taiwan University, Taipei 106, Taiwan \\ Received 23 July 2006; received in revised form 24 April 2007; accepted 20 August 2007 \\ Available online 29 September 2007
}

\begin{abstract}
A small amount of zirconia particles $(\leq 5 \mathrm{vol} . \%)$ is added into alumina in the present study. The grain size of alumina is reduced; the strength of alumina is therefore enhanced. Though the theoretical analysis demonstrates that an addition of 1 vol.\% of fine zirconia particles is sufficient to prohibit the coarsening of alumina grains; the experimental measurements indicate that a minimum amount of 2 vol.\% is required to reduce the coarsening of alumina matrix and its size distribution. This discrepancy is due to the separation between the zirconia particles and alumina grain boundaries, which takes place when the alumina grain size increases above a critical value.

(C) 2007 Elsevier Ltd and Techna Group S.r.l. All rights reserved.
\end{abstract}

Keywords: A. Sintering; B. Microstructure-final; C. Strength; D. $\mathrm{Al}_{2} \mathrm{O}_{3}$; D. $\mathrm{ZrO}_{2}$

\section{Introduction}

Ceramics are brittle in nature. Such brittleness limits many applications involving using ceramics as engineering components. To improve the toughness of ceramics, there has been much work in the last several decades. Since an increase of strength also improves the possibility of brittle ceramics to survive external impacts, increasing the strength of ceramic is also an important task.

Several relationships have been derived to describe the strength, $\sigma$, of brittle ceramics [1,2]. One relationship is that proposed by Griffith:

$\sigma=\frac{K_{\mathrm{IC}}}{Y \sqrt{C}}$

In the above equation, $K_{\mathrm{IC}}$ is the toughness, $Y$ a geometrical constant, and $C$ is the flaw size. The above relationship demonstrates that the strength of a ceramic depends strongly on its flaw size and grain size.

The reduction of flaw size can be achieved by controlling each processing step carefully [3]. The decrease of grain size can be reached through the addition of second phase particles [4-8]. The inhibitors can be oxides [5], non-oxides [4,6] or metallic particles $[7,8]$. These particles should be relatively

\footnotetext{
* Corresponding author. Tel.: +886 23659800; fax: +886 223634562.

E-mail address: tuan@ccms.ntu.edu.tw (W.-H. Tuan).
}

inert to the ceramic matrix during sintering at elevated temperature. Among the composite systems investigated, alumina-zirconia systems have attracted wide attention. The solubility between alumina and zirconia is low $(2000 \mathrm{ppm}$ at $1450{ }^{\circ} \mathrm{C}$ [9]), and the engineering potential of the composites is high. In the present study, the alumina-zirconia system is also used as a model system to explore the rule of microstructure design for strength enhancement.

The first study on the $\mathrm{Al}_{2} \mathrm{O}_{3}-\mathrm{ZrO}_{2}$ system employed a minimum amount of $2 \mathrm{vol} . \% \mathrm{ZrO}_{2}$ particles to enhance the toughness of $\mathrm{Al}_{2} \mathrm{O}_{3}$ [5]. The study demonstrated that the toughness of $\mathrm{Al}_{2} \mathrm{O}_{3}$ could be enhanced only when the $\mathrm{ZrO}_{2}$ content was higher than $5 \mathrm{vol} \%$. Many studies were then performed to confirm this approach [10-14]. Most studies have added more than 5 vol. $\% \mathrm{ZrO}_{2}$ into $\mathrm{Al}_{2} \mathrm{O}_{3}$. They have demonstrated that both the toughness and strength of alumina are improved; nevertheless, the sinterability of the ceramic matrix is reduced when a large amount of second phase is added [15]. Furthermore, the cost of the composites is also increased.

In order to cope with the drop of sintering activity and the increase of cost, a small amount, $<5 \mathrm{vol} . \%$, of second phase is therefore of interest. Such an approach has received little attention in previous studies. One limited study indicated that the properties were not improved by using a small amount, $<5$ vol.\%, of particles [5]. The dilemma on designing ceramic matrix composite is thus apparent. On the one hand, as the second phase content is low, the sintering activity is little affected. But the properties improvement is suspected to be also 
small (it will be demonstrated that this may not be the case). On the other hand, when the second phase content is high, the mechanical properties are improved. However, the cost increase associated with the material hinders the application potential of the composites.

In the present study, a small amount of $\mathrm{ZrO}_{2}$ particles, $\leq 5$ vol. $\%$, is added into $\mathrm{Al}_{2} \mathrm{O}_{3}$. The microstructure of the composites is carefully investigated. The minimum required amount of second phase is suggested in terms of achieving strength enhancement.

\section{Experimental}

An alumina $\left(\mathrm{TM}-\mathrm{DAR}, d_{50}=140 \mathrm{~nm}\right.$, Taimei Chem. Co. Ltd., Nagno-ken, Japan) powder was ball milled together with 0-5 vol.\% zirconia powder (TZ-3Y, $\mathrm{ZrO}_{2}+3 \mathrm{~mol} \% \mathrm{Y}_{2} \mathrm{O}_{3}$, $d_{50}=230 \mathrm{~nm}$, Tosoh Co., Japan) in ethyl alcohol for $24 \mathrm{~h}$, using $10 \mathrm{~mm}$ diameter zirconia balls as grinding media. The slurry of the powder mixtures was dried with a rotary evaporator, and then the dried lumps were crushed and passed through a plastic sieve. Powder compacts with dimensions of $7 \mathrm{~mm} \times 6 \mathrm{~mm} \times$ $50 \mathrm{~mm}$ were formed by uniaxially pressing at $44 \mathrm{MPa}$. Sintering was carried out in a box furnace at $1600{ }^{\circ} \mathrm{C}$ for $1 \mathrm{~h}$ in air with heating rate of $5{ }^{\circ} \mathrm{C} / \mathrm{min}$. A number of disc samples with a diameter of $6 \mathrm{~mm}$ in diameter were prepared for a kinetic study with a dilatometer (SETSYS 1600, TMA, Setaram Co., Caluire, France). The heating rate for the dilatometer was also $5{ }^{\circ} \mathrm{C} / \mathrm{min}$.

The sintered rectangular bars were ground longitudinally with a 325 grit resin-bonded diamond wheel at a depth of $5 \mu \mathrm{m}$ per pass. The final dimensions of the specimens were $3 \mathrm{~mm} \times 4 \mathrm{~mm} \times 36 \mathrm{~mm}$. The strength of the specimens was determined using a four-point bend test carried out at ambient conditions. The upper and lower spans were $10 \mathrm{~mm}$ and $30 \mathrm{~mm}$, respectively. The rate of loading was $0.5 \mathrm{~mm} / \mathrm{min}$. The fracture toughness was determined by the single-edge-notched-beam (SENB) technique. The notch was generated by cutting with a diamond saw. The width of the notch was approximately $0.3 \mathrm{~mm}$.

Phase identification was performed on sintered and fractured surfaces by X-ray diffractometry (XRD) with $\mathrm{Cu}$ $\mathrm{K} \alpha$ radiation. The relative phase content of zirconia was estimated by using the method proposed by Evans et al. [16]. The final density of the specimens was determined by the Archimedes method. The solubility between the materials used in the present study was low; the relative density of the sintered composites was estimated by using the theoretical density of $3.98 \mathrm{~g} / \mathrm{cm}^{3}$ for $\mathrm{Al}_{2} \mathrm{O}_{3}$ and $6.05 \mathrm{~g} / \mathrm{cm}^{3}$ for $\mathrm{ZrO}_{2}$. Polished surfaces for microstructure observation were prepared by grinding and polishing with diamond paste to $6 \mu \mathrm{m}$ and with silica suspension to $0.05 \mu \mathrm{m}$. The polished specimens were thermally etched at $1450{ }^{\circ} \mathrm{C}$ for $0.5 \mathrm{~h}$ to reveal the grain boundaries of matrix grains. Microstructure characterization was conducted using scanning electron microscopy (SEM). Image analysis was conducted on SEM micrographs to determine the average size of $\mathrm{Al}_{2} \mathrm{O}_{3}$ grains and their size distribution.

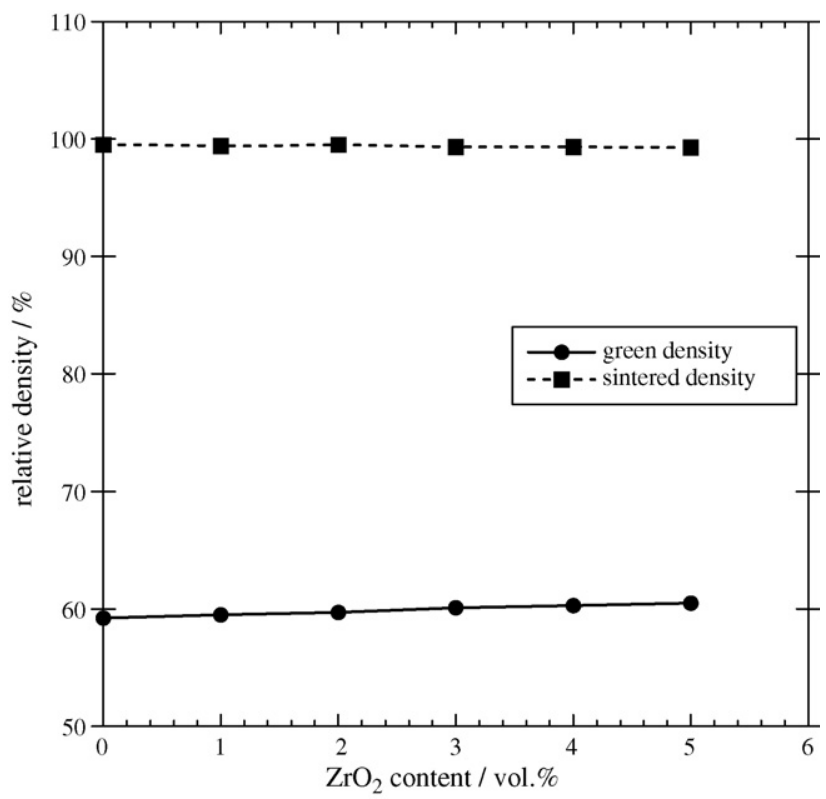

Fig. 1. Green and sintered density of the $\mathrm{Al}_{2} \mathrm{O}_{3} / \mathrm{ZrO}_{2}$ composites.

\section{Results}

The density of the green powder compacts increases slightly from $59.5 \%$ to $60.5 \%$ with the $\mathrm{ZrO}_{2}$ content varies from zero to five vol. $\%$ (see Fig. 1). The densities of the sintered $\mathrm{Al}_{2} \mathrm{O}_{3} / \mathrm{ZrO}_{2}$ composites are all higher than 99\%. Fig. 2 shows the XRD patterns of the $\mathrm{Al}_{2} \mathrm{O}_{3}$ and $\mathrm{Al}_{2} \mathrm{O}_{3} / 5 \% \mathrm{ZrO}_{2}$ composite. XRD analysis shows only $\mathrm{Al}_{2} \mathrm{O}_{3}$ and $\mathrm{ZrO}_{2}$ phases in the sintered $\mathrm{Al}_{2} \mathrm{O}_{3} / \mathrm{ZrO}_{2}$ composites. Fig. 3(a) shows the linear shrinkage of the $\mathrm{Al}_{2} \mathrm{O}_{3} / \mathrm{ZrO}_{2}$ composites during sintering. The presence of the $\mathrm{ZrO}_{2}$ particles delays the shrinkage of $\mathrm{Al}_{2} \mathrm{O}_{3}$ in the temperature range from 1000 to $1400{ }^{\circ} \mathrm{C}$. However, the temperature at the peak densification rate (the second peak in Fig. 3b) remains the same. The densification for all the composites is almost complete as the temperature reaches $1450{ }^{\circ} \mathrm{C}$.

Fig. 4 shows typical SEM images of the specimens. These micrographs demonstrate that the addition of $\mathrm{ZrO}_{2}$ particles

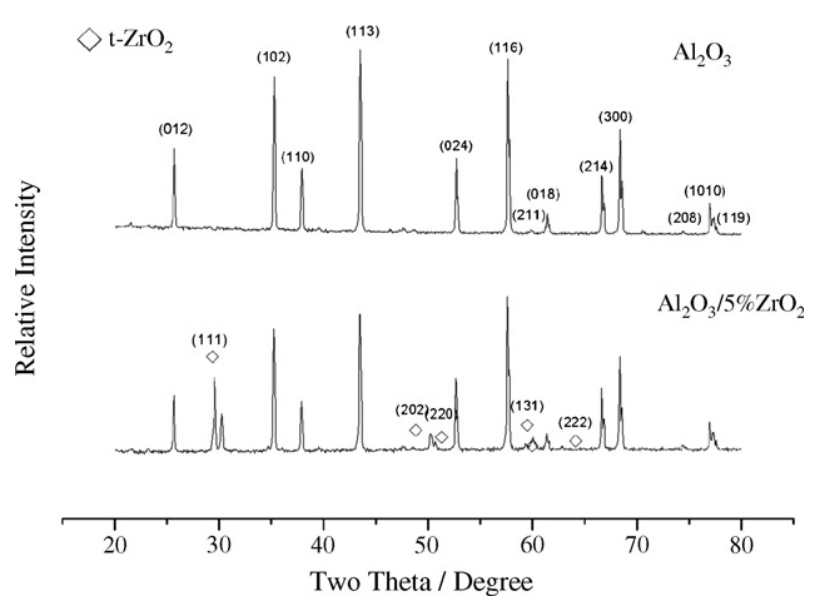

Fig. 2. XRD patterns of pure $\mathrm{Al}_{2} \mathrm{O}_{3}$ and $\mathrm{Al}_{2} \mathrm{O}_{3} / 5 \% \mathrm{ZrO}_{2}$ composite. 

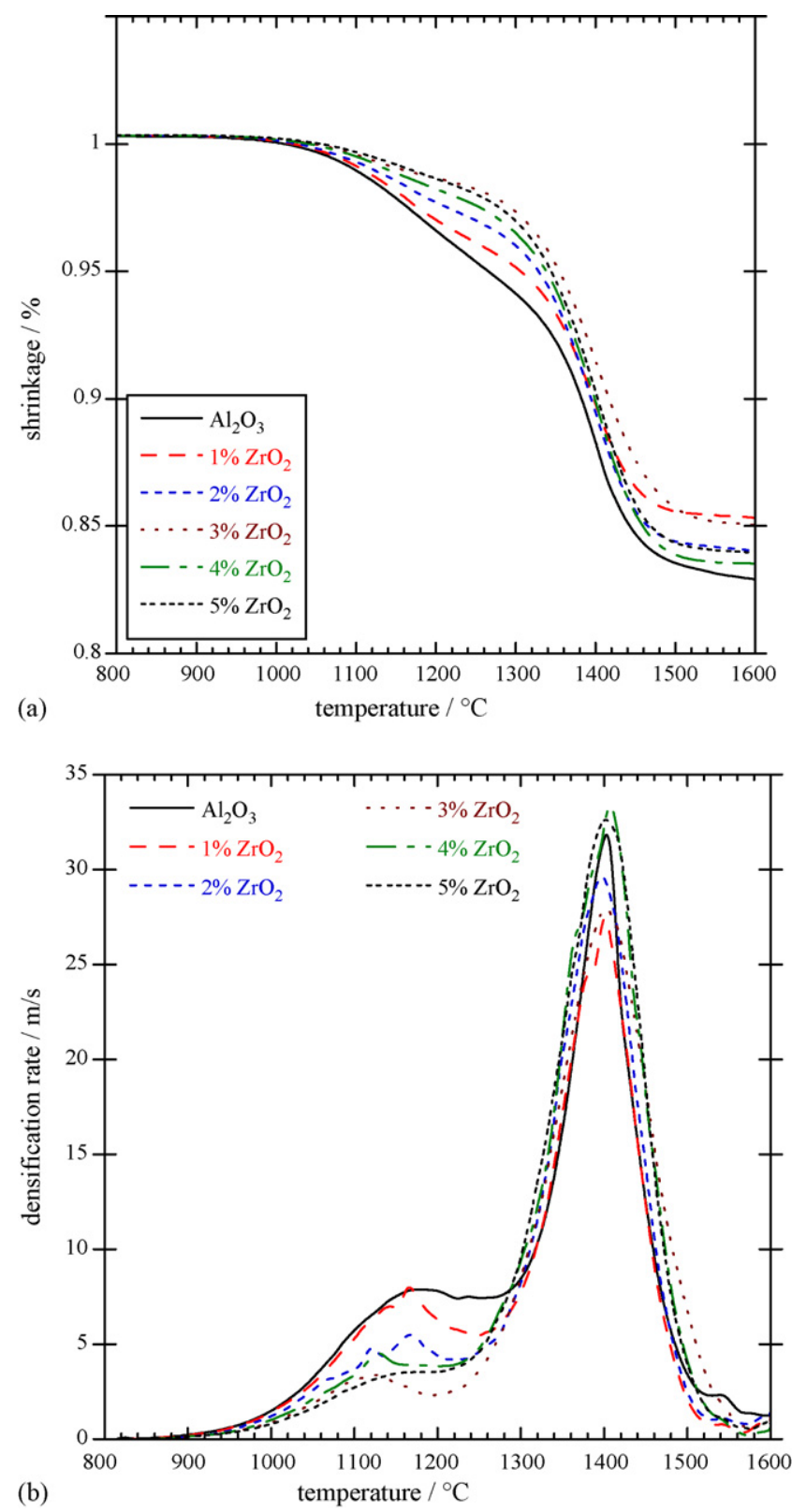

Fig. 3. (a) Percent shrinkage and (b) densification rate as function of temperature for various $\mathrm{Al}_{2} \mathrm{O}_{3} / \mathrm{ZrO}_{2}$ composites.

reduces the size of $\mathrm{Al}_{2} \mathrm{O}_{3}$ grains (see Table 1). In the $\mathrm{Al}_{2} \mathrm{O}_{3} / 1 \%$ $\mathrm{ZrO}_{2}$ composite (see Fig. 4b), most $\mathrm{ZrO}_{2}$ particles are embedded within the $\mathrm{Al}_{2} \mathrm{O}_{3}$ grains. For the composites containing more than 2 vol. $\% \mathrm{ZrO}_{2}$, the particles are mainly at the boundaries of the $\mathrm{Al}_{2} \mathrm{O}_{3}$ matrix grains (see Fig. $4 \mathrm{c}-\mathrm{f}$ ). The size of $\mathrm{ZrO}_{2}$ particles is about $0.3 \mu \mathrm{m}$ which is more or less the same in all the $\mathrm{Al}_{2} \mathrm{O}_{3} / \mathrm{ZrO}_{2}$ composites. Nevertheless, some $\mathrm{ZrO}_{2}$ agglomerates are found occasionally (see Fig. 4e). The $\mathrm{ZrO}_{2}$ grains in the agglomerate are larger than the isolated $\mathrm{ZrO}_{2}$ particles. Fig. 5 shows the size distribution of $\mathrm{Al}_{2} \mathrm{O}_{3}$ grains for the $\mathrm{Al}_{2} \mathrm{O}_{3}$ and $\mathrm{Al}_{2} \mathrm{O}_{3} / \mathrm{ZrO}_{2}$ specimens. When the $\mathrm{ZrO}_{2}$ content is higher than 2 vol.\%, the addition of a small amount of $\mathrm{ZrO}_{2}$ reduces not only the average size of $\mathrm{Al}_{2} \mathrm{O}_{3}$ grains but also their distribution. In the $\mathrm{Al}_{2} \mathrm{O}_{3} / \mathrm{ZrO}_{2}$ composite with $1 \% \mathrm{ZrO}_{2}$, several large grains are still present (Figs. $4 \mathrm{~b}$ and 5).
Fig. 6 shows the flexural strength of the $\mathrm{Al}_{2} \mathrm{O}_{3} / \mathrm{ZrO}_{2}$ composites as a function of $\mathrm{ZrO}_{2}$ content. The flexural strength of the composites increases with the increase of $\mathrm{ZrO}_{2}$ content. Apart from the dependence on the $\mathrm{ZrO}_{2}$ content, the strength as expected also shows strong dependence on the size of $\mathrm{Al}_{2} \mathrm{O}_{3}$ grains (see Fig. 7). Fig. 8 shows the fracture toughness of the $\mathrm{Al}_{2} \mathrm{O}_{3} / \mathrm{ZrO}_{2}$ composites as a function of $\mathrm{ZrO}_{2}$ content. The XRD analysis shows that around $30 \%$ of the $\mathrm{ZrO}_{2}$ particles on the fracture surface of the $\mathrm{Al}_{2} \mathrm{O}_{3} / 5 \% \quad \mathrm{ZrO}_{2}$ composites is transformed from tetragonal to monoclinic phase, indicating that transformation toughening is active in the composites.

\section{Discussion}

Two peaks, a small peak at $1160{ }^{\circ} \mathrm{C}$ and a larger one at $1400{ }^{\circ} \mathrm{C}$, are found in the sintering kinetic curves (see Fig. 3b). The first peak can be related to the presence of $\mathrm{Al}_{2} \mathrm{O}_{3}$ agglomerates due to the fact that intra-agglomerate pores are usually small [17]. The addition of more than 2 vol.\% $\mathrm{ZrO}_{2}$ particles reduces the height of the first peak, suggesting that the $\mathrm{Al}_{2} \mathrm{O}_{3}$ agglomerates are dispersed due to the presence of $\mathrm{ZrO}_{2}$ particles. The reduction of agglomerate can contribute to the reduction of flaw size [3]; the strength of the alumina is therefore enhanced.

Through microstructure observation shown in Fig. 4 indicates that the $\mathrm{ZrO}_{2}$ particles act as effective grain growth inhibitors to $\mathrm{Al}_{2} \mathrm{O}_{3}$. The size of alumina grains reduces from $5.5 \mu \mathrm{m}$ (for pure alumina) to $2.2 \mu \mathrm{m}$ (for $\mathrm{Al}_{2} \mathrm{O}_{3} / 5 \% \mathrm{ZrO}_{2}$ composite). Except the $\mathrm{Al}_{2} \mathrm{O}_{3} / 1 \% \mathrm{ZrO}_{2}$ composite, the size scatter of the $\mathrm{Al}_{2} \mathrm{O}_{3}$ grains in the composites is also reduced.

Most $\mathrm{ZrO}_{2}$ particles are well separated within the $\mathrm{Al}_{2} \mathrm{O}_{3}$ matrix. Since the coarsening of $\mathrm{ZrO}_{2}$ particles can then take place only through the diffusion within the $\mathrm{Al}_{2} \mathrm{O}_{3}$ matrix, this is a relatively slow process. Therefore, the size of zirconia particles is more or less the same in all the $\mathrm{Al}_{2} \mathrm{O}_{3} / \mathrm{ZrO}_{2}$ composites, indicating that the coarsening of well-dispersed $\mathrm{ZrO}_{2}$ inclusions is limited. Such limited coarsening can be related to the low $\mathrm{ZrO}_{2}$ content used in the present study. The coarsening of $\mathrm{ZrO}_{2}$ particles is found only in the $\mathrm{ZrO}_{2}$ agglomerate (see Fig. 4e).

For a composite containing mono-sized inclusions, the grain size decreases with the increase of particle content (Zener effect). The nearest neighbor distance (or mean free path), $\lambda$, between randomly distributed particles can be estimated with the following relationship proposed by Westmacott et al. [18] and Kock [19];

$\lambda=\left(\frac{\pi}{6}\right)^{1 / 2} \frac{d}{F^{1 / 2}}$

where $d$ is the size of particle and $F$ is the volume fraction. The calculated values for the distance between nearest neighboring $\mathrm{ZrO}_{2}$ particles in $\mathrm{Al}_{2} \mathrm{O}_{3}$ matrix are shown in Table 1 . The table indicates that the mean free path between the $\mathrm{ZrO}_{2}$ particles in all the $\mathrm{Al}_{2} \mathrm{O}_{3} / \mathrm{ZrO}_{2}$ composites is shorter than the corresponding size of the $\mathrm{Al}_{2} \mathrm{O}_{3}$ grains. 
(a)

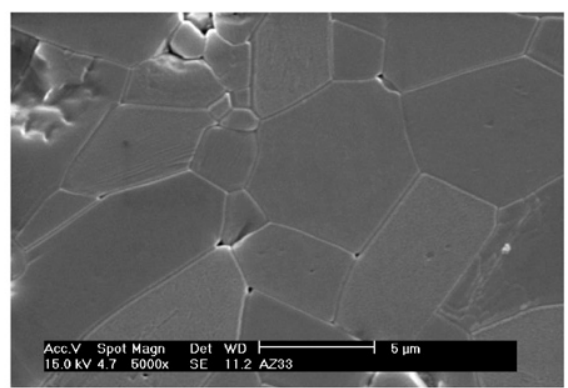

(c)

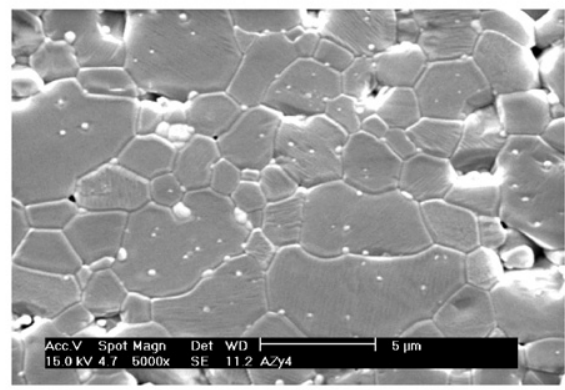

(e)

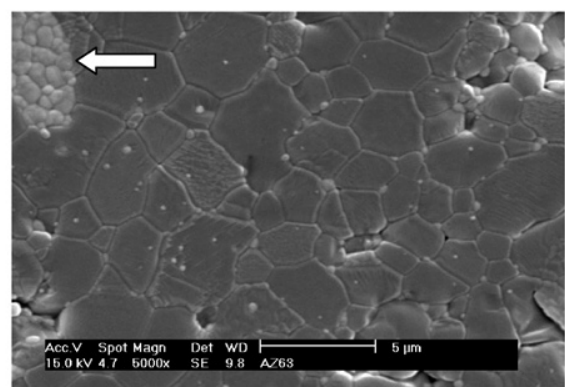

(b)

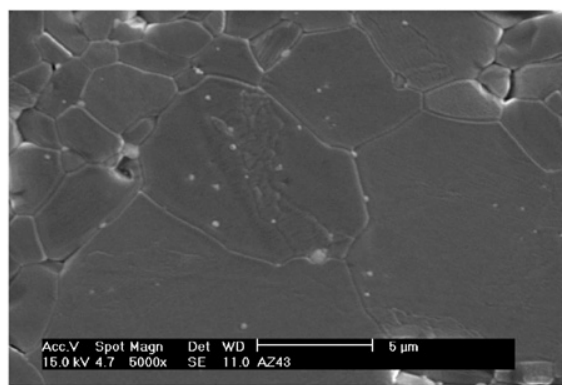

(d)

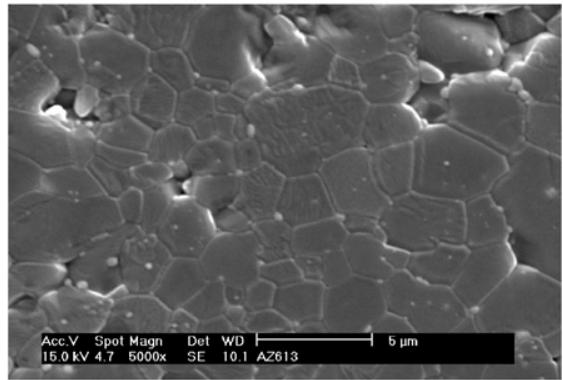

(f)

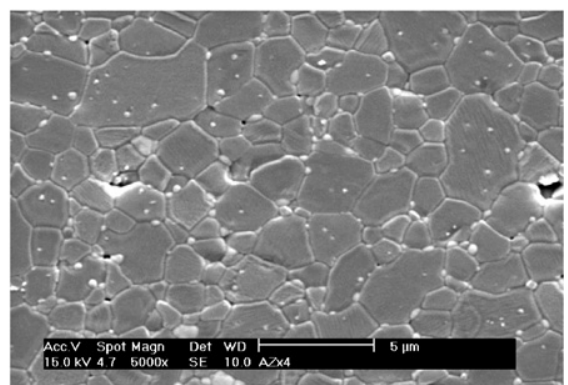

Fig. 4. SEM images of the (a) $\mathrm{Al}_{2} \mathrm{O}_{3}$, (b) $\mathrm{Al}_{2} \mathrm{O}_{3} / 1 \% \mathrm{ZrO}_{2}$, (c) $\mathrm{Al}_{2} \mathrm{O}_{3} / 2 \% \mathrm{ZrO}_{2}$, (d) $\mathrm{Al}_{2} \mathrm{O}_{3} / 3 \% \mathrm{ZrO}_{2}$, (e) $\mathrm{Al}_{2} \mathrm{O}_{3} / 4 \% \mathrm{ZrO}_{2}$, and (f) $\mathrm{Al}_{2} \mathrm{O}_{3} / 5 \% \mathrm{ZrO}_{2}$ composites. $\mathrm{An}$ agglomerate of $\mathrm{ZrO}_{2}$ in (e) is indicated with arrow.

It is thus of interest to estimate the minimum amount of second phase particles needed to prohibit the growth of matrix grains. By assuming that one particle is enough to prohibit the movement of one grain boundary, then $\lambda \sim G(G=$ size of matrix grains). The amount of particle needed to prohibit the growth of matrix grains can be estimated by re-arranging Eq. (2) as,

$F^{1 / 2}=\left(\frac{\pi}{6}\right)^{1 / 2} \frac{d}{G}$

For the microstructure shown in Fig. 9(a), each grain boundary of matrix grains (white grains) is pinned by one

Table 1

Microstructure characteristics of the $\mathrm{Al}_{2} \mathrm{O}_{3} / \mathrm{ZrO}_{2}$ composites

\begin{tabular}{llll}
\hline & $\begin{array}{l}\text { Average size } \\
\text { of } \mathrm{Al}_{2} \mathrm{O}_{3} \text { grains }(\mu \mathrm{m})\end{array}$ & $\begin{array}{l}\text { Standard deviation/ } \\
\text { coefficient of variation }\end{array}$ & $\begin{array}{l}\text { Mean free path between } \\
\mathrm{ZrO}_{2} \text { particles }^{\mathrm{b}}(\mu \mathrm{m})\end{array}$ \\
\hline $\mathrm{Al}_{2} \mathrm{O}_{3}$ & 5.5 & $2.5 / 45 \%$ & - \\
$\mathrm{Al}_{2} \mathrm{O}_{3} / 1 \% \mathrm{ZrO}_{2}$ & 3.8 & $1.9 / 50 \%$ & 2.2 \\
$\mathrm{Al}_{2} \mathrm{O}_{3} / 2 \% \mathrm{ZrO}_{2}$ & 3.0 & $1.2 / 40 \%$ & 1.5 \\
$\mathrm{Al}_{2} \mathrm{O}_{3} / 3 \% \mathrm{ZrO}_{2}$ & 3.0 & $1.2 / 40 \%$ & 1.3 \\
$\mathrm{Al}_{2} \mathrm{O}_{3} / 4 \% \mathrm{ZrO}_{2}$ & 2.6 & $1.0 / 38 \%$ & 1.1 \\
$\mathrm{Al}_{2} \mathrm{O}_{3} / 5 \% \mathrm{ZrO}_{2}$ & 2.2 & $0.76 / 35 \%$ & 1.0 \\
\hline
\end{tabular}

\footnotetext{
${ }^{\mathrm{a}}$ Coefficient of variation $=$ standard deviation/average value.

${ }^{\mathrm{b}}$ Calculated by using Eq. (1); the size of $\mathrm{ZrO}_{2}$ particle $\sim 0.3 \mu \mathrm{m}$.
}

particle (dark particle). As the size of particle is the same as that of matrix grains, the particle content is around $50 \mathrm{vol} . \%$. Though the microstructure should be stable throughout the sintering process, such high particle content can, not only prohibit the grain growth but also limit the sintering activity of the ceramic matrix grains. Therefore, the amount of the second phase should be lower than 50 vol.\%.

As the particle size is reduced to one tenth that of matrix grains, Fig. 9(b), a volume fraction of 0.5 vol. $\%$ is obtained by using Eq. (3). If the $d / G$ ratio is further decreased to 0.01 , the amount of second phase can then be reduced to 0.005 vol.\%. The analysis implies that the amount of 1 vol.\% particle may be 


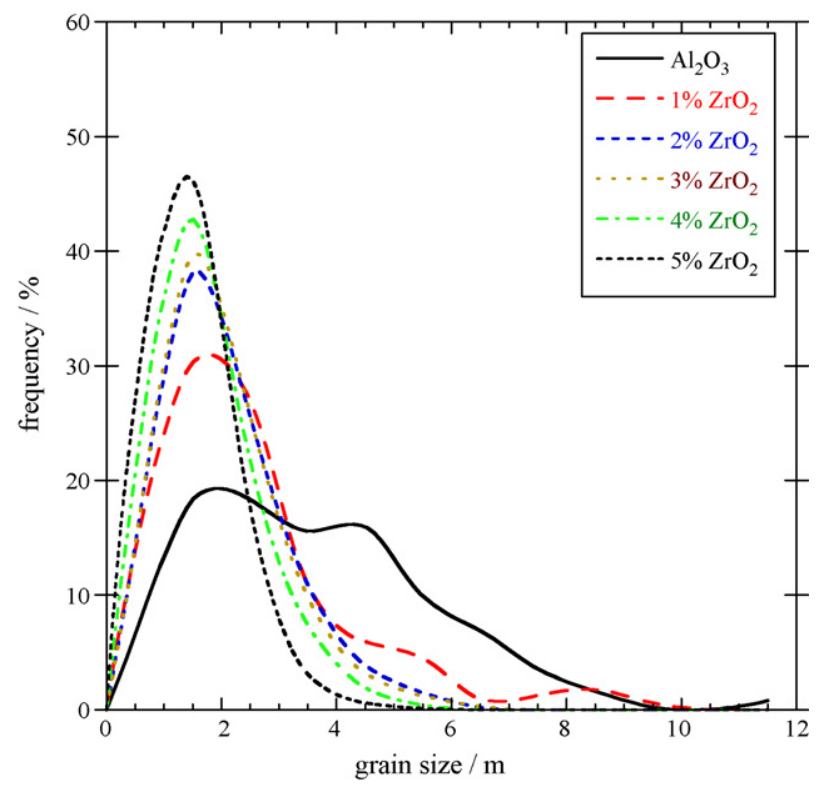

Fig. 5. Size distribution of $\mathrm{Al}_{2} \mathrm{O}_{3}$ grains in the $\mathrm{Al}_{2} \mathrm{O}_{3} / \mathrm{ZrO}_{2}$ composites.

more than enough to prohibit the grain growth of $\mathrm{Al}_{2} \mathrm{O}_{3}$ matrix. However, as the $d / G$ value is too low, it may encourage the separation of the particle and grain boundary, as demonstrated in the $\mathrm{Al}_{2} \mathrm{O}_{3} / 1$ vol.\% $\mathrm{ZrO}_{2}$ composite (see Fig. 4b). In the composite, most $\mathrm{ZrO}_{2}$ particles are separated from the grain boundaries of $\mathrm{Al}_{2} \mathrm{O}_{3}$ grains. The $\mathrm{ZrO}_{2}$ particles with such low amount can no longer prohibit the growth of matrix grains; several coarse grains are thus survived after sintering (see Fig. 5). In order to prohibit the movement of grain boundary, the particle is preferably located at the grain boundary as the case shown in Fig. 9(a) and (b). The case as demonstrated in Fig. 9(c) should be avoided. Therefore, the criteria for the separation of secondary particles and grain boundary should be investigated.

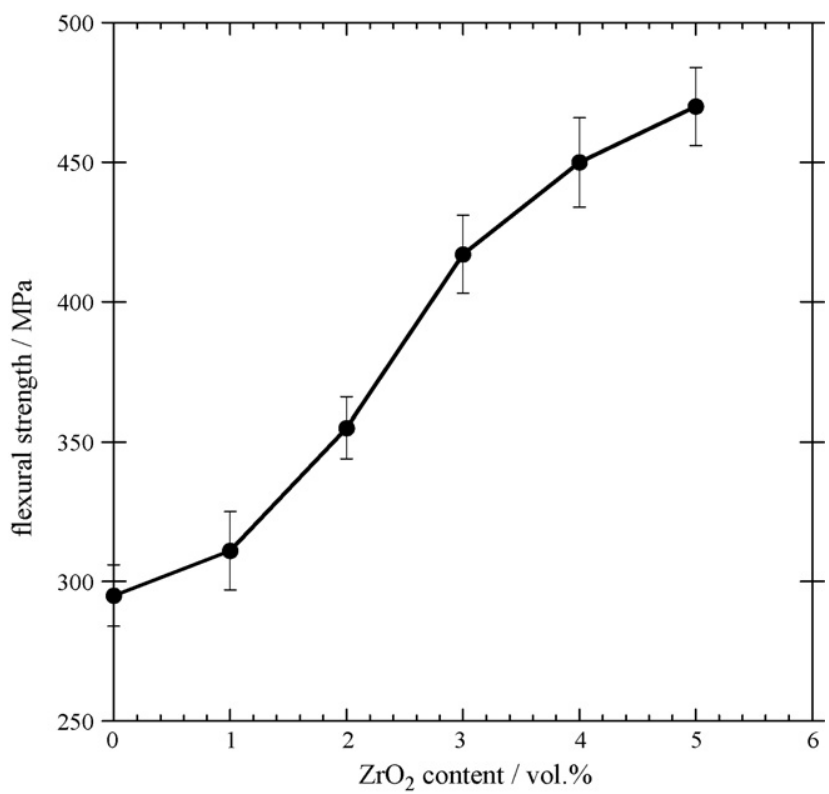

Fig. 6. Flexural strength of the composites as function of $\mathrm{ZrO}_{2}$ content.

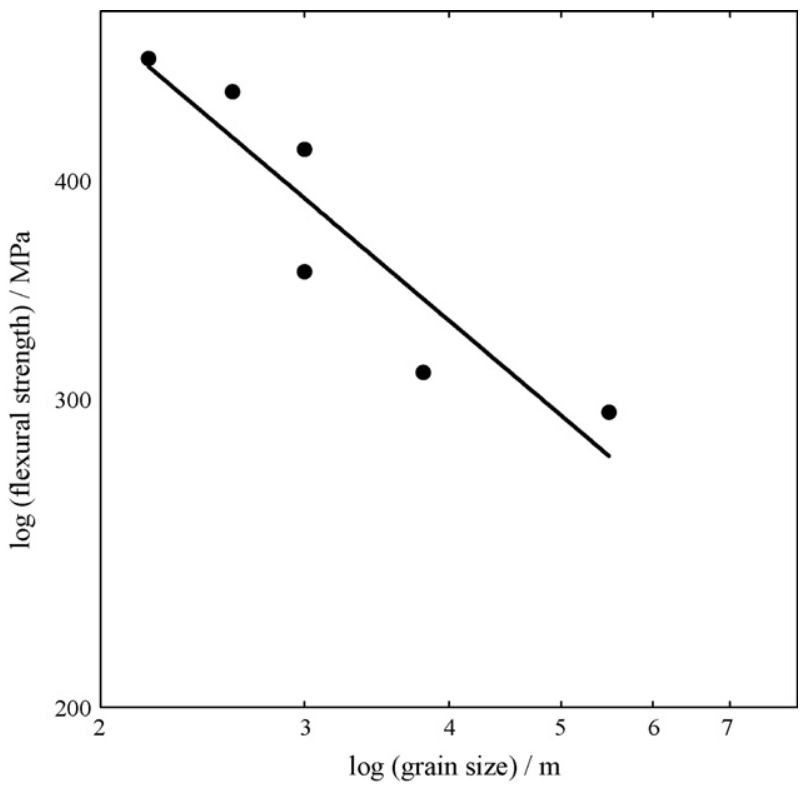

Fig. 7. Flexural strength of the $\mathrm{Al}_{2} \mathrm{O}_{3} / \mathrm{ZrO}_{2}$ composites as function of $\mathrm{Al}_{2} \mathrm{O}_{3}$ grain size.

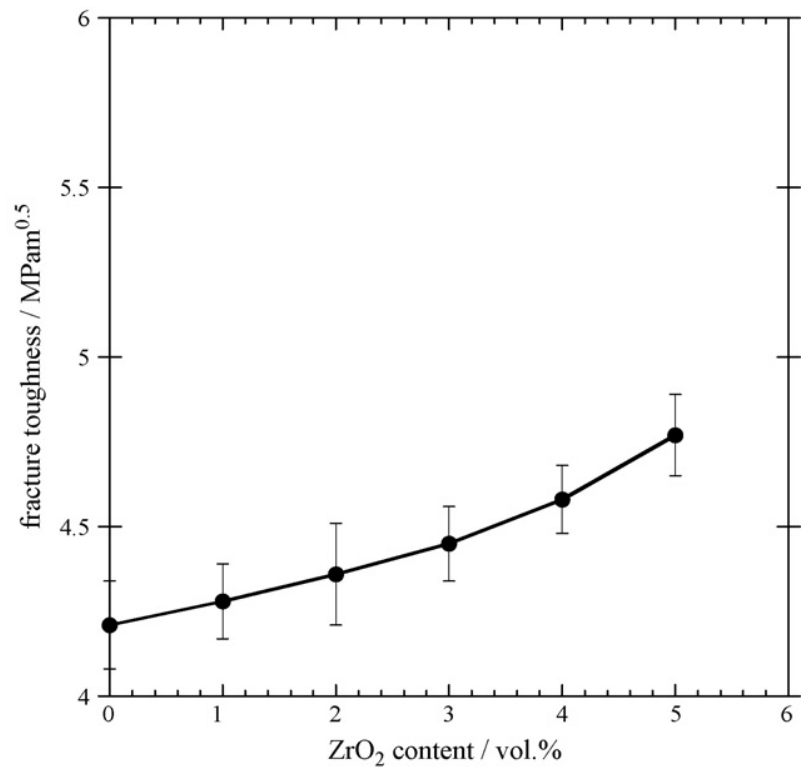

Fig. 8. Fracture toughness of the composites as function of $\mathrm{ZrO}_{2}$ content.

During sintering, with the help of a number of transport mechanisms the matrix grains can grow with the help from the movement of grain boundary. The velocity of the grain boundary movement is virtually the same as the grain growth rate. As the velocity of grain boundary, $v_{\mathrm{b}}$, is much higher than that of particle, $v_{\mathrm{p}}$, the separation can take place (see Fig. 10). The following relationship defines the criteria for the separation to take place:

$v_{\mathrm{b}}>v_{\mathrm{p}}^{\max }$

In order for the particle and grain boundary to move, the velocity is contributed by mobility, $M$, and force, $F$, as

$v=M F$ 
(a)

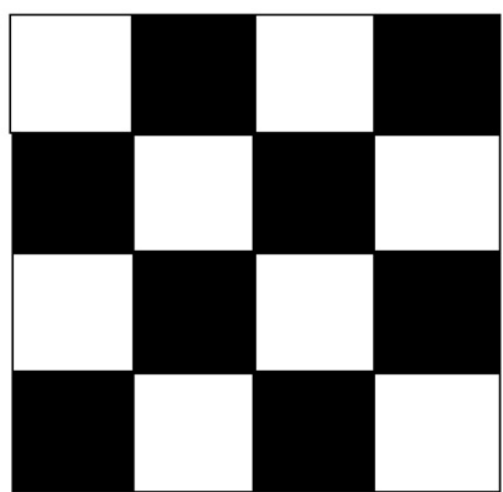

(b)

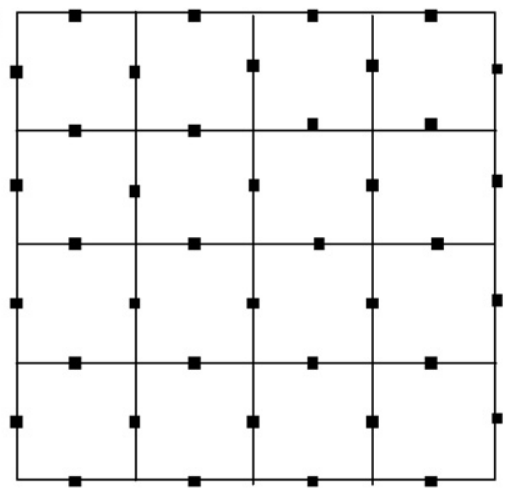

(c)

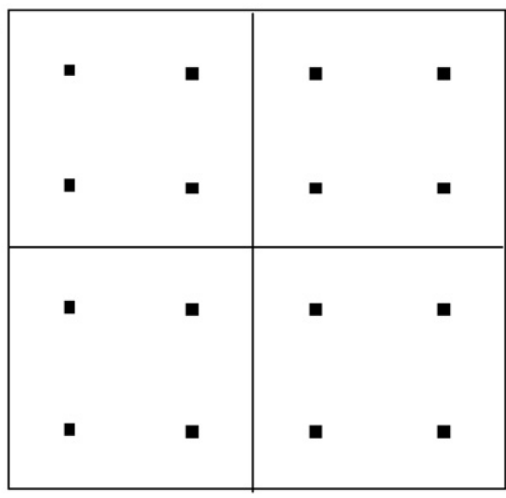

Fig. 9. Interactions between grain boundary and second phase particles; showing (a) both matrix and the particles are the same size and (b) much smaller interboundary particles. The particles in (c) fail to pin the grain boundaries due to the matrix grains are larger than a critical value.

For the grain boundary, its mobility is controlled by the diffusion across the grain boundary, $D^{*}$, the Boltzmann's constant, $k$, and the absolute temperature, $T$. The force on the grain boundary is controlled by the grain boundary energy, $\gamma_{\mathrm{gb}}$, and grain size, $G$. The velocity of boundary, $v_{\mathrm{b}}$, can then be expressed as [20];

$v_{\mathrm{b}}=M_{\mathrm{b}} F_{\mathrm{b}}=\frac{D^{*}}{k T} \frac{\gamma_{\mathrm{gb}}}{G}$

For the particle, mass can transport along the interface or the interior of the particle or both. Therefore, an effective diffusion coefficient, $D_{\text {eff }}$, to illustrate the mobility of the particle is used instead as [20];

$M_{\mathrm{p}}=\frac{D_{\mathrm{eff}} \Omega}{k T d^{n}}$

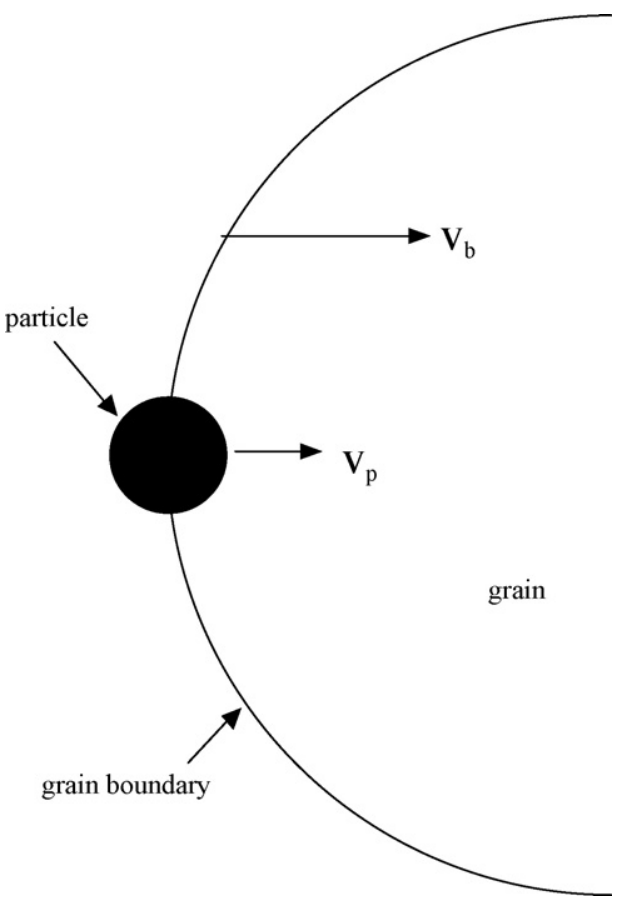

Fig. 10. Interaction between a moving grain boundary and a moving particle.

where $\Omega$ is the volume of controlling ions and $n$ is a constant depending on the mechanism. The force on the particle is also provided by the grain boundary energy. By using the relationship to estimate the force on an isolated pore [20], the force on a particle is estimated as

$F_{\mathrm{p}}=2 \pi d \gamma_{\mathrm{gb}}$

The velocity of particle, $v_{\mathrm{p}}$, is

$v_{\mathrm{p}}=M_{\mathrm{p}} F_{\mathrm{p}}=\frac{D_{\mathrm{eff}} \Omega}{k T d^{n}} 2 \pi d \gamma_{\mathrm{gb}}$

By comparing Eqs. (6) and (9), the following equation is obtained:

$\frac{D^{*}}{2 \pi D_{\mathrm{eff}} \Omega}>\frac{G}{d^{n-1}}$

The analysis above demonstrates that there is a critical value for the ratio of grain size over particle size. Since the grains grow rapidly as the density is higher than around $80 \%$ [20]. Along with the grain growth, the ratio of grain size over particle size also increases. Since the coarsening of particles is limited as the second phase amount is low, the separation between the grain boundary and particle is virtually controlled by the growth of matrix grains. From the microstructure observation, the critical size for the $\mathrm{Al}_{2} \mathrm{O}_{3}$ grain to separate from the $\mathrm{ZrO}_{2}$ particle is around $4 \mu \mathrm{m}$. Since the $\mathrm{ZrO}_{2}$ particles in all the $\mathrm{Al}_{2} \mathrm{O}_{3} / \mathrm{ZrO}_{2}$ composite are similar in size, the increase of $\mathrm{ZrO}_{2}$ content increases the number of $\mathrm{ZrO}_{2}$ particles. More $\mathrm{ZrO}_{2}$ particles at each grain boundary exert higher dragging force to the movement of grain boundary. The size of alumina grains is thus reduced with the increase of $\mathrm{ZrO}_{2}$ content. 
The analysis above demonstrates that there is a critical amount for the second phase to prohibit the coarsening of matrix grains. The critical amount of the second phase is a function of the ratio of grain size over particle size. In the present study, it demonstrates that the critical amount of second phase depends on the growth of matrix grains, provided that the coarsening of particles is limited. For the present system under the processing conditions used, the critical amount of $\mathrm{ZrO}_{2}$ particles is $2 \mathrm{vol} . \%$. The analysis also suggests that the decrease of particle size can further encourage the separation of grain boundary and particles. If the particles are preferable to be swallowed by the matrix grains in order to leave behind wavy grain boundaries, as is the case for the $\mathrm{Al}_{2} \mathrm{O}_{3} / \mathrm{SiC}$ nanocomposite [21], such target possibly can be achieved either by reducing the particle size or by increasing the grain size through the rise of sintering temperature.

\section{Conclusions}

There are several advantages of using a small amount $(<5 \mathrm{vol} . \%)$ of $\mathrm{ZrO}_{2}$ particles as the strengthening agent to $\mathrm{Al}_{2} \mathrm{O}_{3}$ ceramics.

1. The addition of the fine $\mathrm{ZrO}_{2}$ particles reduces the amount of $\mathrm{Al}_{2} \mathrm{O}_{3}$ agglomerates.

2. The addition of a small amount of $\mathrm{ZrO}_{2}$ particles can also reduce the size of $\mathrm{Al}_{2} \mathrm{O}_{3}$ matrix grains.

3. The strength of $\mathrm{Al}_{2} \mathrm{O}_{3}$ is enhanced due to the reduction of grain size.

4. The coarsening of particles within ceramic matrix is limited as the particle content is lower.

5. The critical amount of particles to prohibit the coarsening of matrix grains is a function of grain size over particle size.

\section{Acknowledgments}

The present study was supported by the National Science Council through the contract numbers of NSC94-2216-E-002014 and NSC94-2216-E-002-016. Valuable comments given by Prof. Jay Shieh, Dept. of Mater. Sci. \& Eng., National Taiwan University, are helpful.

\section{References}

[1] R.W. Rice, Microstructure dependence of mechanical behavior of ceramics, Treatise. Mater. Sci. Tech. 11 (1977) 199-381.

[2] W.H. Tuan, M.J. Lai, M.C. Lin, C.C. Chan, S.C. Chiu, The mechanical performance of alumina as a function of grain size, Mater. Chem. Phys. 36 (1994) 246-251.

[3] W.H. Rhodes, Agglomerate and particle size effect on sintering yttriastabilized zirconia, J. Am. Ceram. Soc. 64 (1981) 19-26.

[4] G.C. Wei, P.F. Becher, Development of SiC-whisker-reinforced ceramics, Am. Ceram. Soc. Bull. 64 (1985) 298-304.

[5] N. Claussen, J. Steeb, R.F. Fabst, Effect of induced microcracking on the fracture toughness of ceramics, Am. Ceram. Soc. Bull. 56 (1977) 559562.

[6] K. Niihara, New design concept of structural ceramic-ceramic nanocomposites, J. Ceram. Soc. Jpn. 99 (1991) 974-982.

[7] W.H. Tuan, R.J. Brook, The toughening of alumina with nickel inclusions, J. Eur. Ceram. Soc. 6 (1990) 31-37.

[8] T. Sekino, T. Nakajima, S. Ueda, K. Niihara, Reduction and sintering of a nickel-dispersed-alumina composite and its properties, J. Am. Ceram. Soc. 80 (1977) 1139-1148.

[9] R. Majumdar, E. Gilbart, R.J. Brook, Kinetics of densification of aluminazirconia ceramics, Br. Ceram. Trans. J. 85 (1993) 156-160.

[10] F.F. Lange, Transformation toughening, IV, fabrication, fracture toughness and strength of $\mathrm{Al}_{2} \mathrm{O}_{3}-\mathrm{ZrO}_{2}$ composites, J. Mater. Sci. 17 (1982) 247-254.

[11] P.F. Becher, Slow crack growth behavior in transformation-toughened $\mathrm{Al}_{2} \mathrm{O}_{3}-\mathrm{ZrO}_{2}\left(\mathrm{Y}_{2} \mathrm{O}_{3}\right)$ ceramics, J. Am. Ceram. Soc. 66 (1983) 485-488.

[12] M. Ruhle, A.G. Evans, R.M. McMeeking, P.G. Charalambides, J.W. Hutchinson, Microcrack toughening in alumina/zirconia, Acta Metall. 25 (1987) 2701-2710.

[13] M. Ruhle, A.G. Evans, High toughness ceramics and ceramic-matrix composites, Prog. Mater. Sci. 33 (1989) 85-167.

[14] R.H.J. Hannink, P.M. Kelly, B.C. Muddle, Transformation toughening in zirconia-containing ceramics, J. Am. Ceram. Soc. 83 (2000) 461-487.

[15] O. Sudre, F.F. Lange, The effect of inclusions on densification: I, microstructural developments in an $\mathrm{Al}_{2} \mathrm{O}_{3}$ matrix containing a large volume fraction of $\mathrm{ZrO}_{2}$ inclusion, J. Am. Ceram. Soc. 75 (1992) 519-524.

[16] P.A. Evans, R. Stevens, J.P. Binner, Quantitative X-ray diffraction analysis of polymorphic mixes of pure zirconia, Br. Ceram. Trans. J. 84 (1984) 39-43.

[17] A. Roosen, H. Hausner, Sintering kinetics of $\mathrm{ZrO}_{2}$ powders, Adv. Ceram. 12 (1984) 714-726.

[18] K.H. Westmacott, C.W. Fountain, R.J. Stirton, On the spacing of dispersed obstacles, Acta Metall. 14 (1966) 1628-1629.

[19] U.F. Kocks, On the spacing of dispersed obstacles, Acta Metall. 14 (1966) 1629-1631.

[20] R.J. Brook, Controlled grain growth, Treatise. Mater. Sci. Tech. 9 (1976) 331-364.

[21] M. Sternitzke, Review: structural ceramic nanocomposites, J. Eur. Ceram. Soc. 17 (1997) 1061-1082. 